\title{
Eclecticism in Chinese Modern Calligraphy, Analysis on Foo Yong Kong's Painting
}

\author{
Tjutju Widjaja ${ }^{1 *}$ Setiawan Sabana ${ }^{2}$ Ira Adriati $^{3}$ \\ 1. Faculty of Art and Design, Bandung Institute of Technology, Jl. Ganesha No. 10, Bandung, Indonesia, \\ 40132 \\ 2. Faculty of Art and Design, Bandung Institute of Technology, Jl. Ganesha No. 10, Bandung, Indonesia, \\ 40132 \\ 3. Faculty of Art and Design, Bandung Institute of Technology, J1. Ganesha No. 10, Bandung, Indonesia, \\ 40132 \\ * E-mail of the corresponding author: tjutjuw@gmail.com
}

\begin{abstract}
Foo Yong Kong is a unique artist, in his artistic practice, he mixes the art of calligraphy with the abstract art of expressionism. Chinese calligraphy is a form of Chinese traditional art. Abstract expressionism is one of the idioms of modern art. In modern art discourse, calligraphy is not categorized as fine art. As part of the identity of the Chinese nation for centuries, the existence of Chinese calligraphy art has been experiencing various developments. One phenomenal development is about how calligraphy redefine itself within modern art discourse which has led to a renewal of Chinese modern calligraphy. This study aims to analyze Foo Yong Kong's paintings in the perspective of Chinese modern calligraphy discourse with a focus on aesthetic tendencies in his works. The results show the tendency of eclecticism in Foo Yong Kong's artwork that combines aesthetic elements in calligraphy such as black brush stroke resulting from the effects of using special brushes ( $m a o b i)$ and solid ink ( $m o$ ), ink stone (yantai) and paper (xian zhi), with the practice of action painting using acrylic paint with contrasting colours.
\end{abstract}

Keywords: Chinese Calligraphy, Abstract Expressionism, Eclecticism, Foo Yong Kong, Modern Chinese Calligraphy

DOI: $10.7176 / \mathrm{ADS} / 81-05$

Publication date:April $30^{\text {th }} 2020$

\section{Introduction}

Chinese Calligraphy is a traditional art that has existed for thousands of years. There is no valid history about the beginning of the practice of calligraphy. The site Britannica (2016) relates the early history of calligraphy with the discovery of the distinctive style of modern Chinese characters writing known as the lishu style. The emergence of this style emerged along with the success of the emperor Shi Huangdi conquering the entire China and uniting them under one government. Emperor Shi Huangdi carried out several reforms, one of which was the unification of the official character of the country initiated by Li Si, who was the Prime Minister at that time. Lishu is a style that is increasingly being used in the Qin Dynasty and is very dominantly used officially during the Han Dynasty. Lishu's characters are easily recognizable and readable, even for readers in the modern era. The letters have flat characters and square lines. The beauty and easily readable makes Lishu still used as Headlines in newspapers or billboards in the current era.

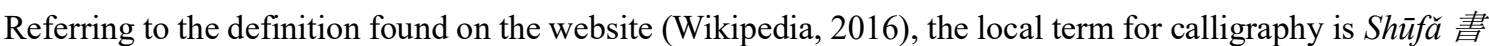
法, which in Chinese means the method / rule of writing. While the website tionghoa (2016) explains the definition of Chinese calligraphy as the art of writing Chinese characters (Hanzi), using ink that is poured into writing medium. Chinese Calligraphy is one type or category of art, in Chinese: yishu, this means that calligraphy is appreciated based on its aesthetic quality. The words that are the subject of writing in Chinese calligraphy can be in the form of prayer, philosophy, and even folklore. Even so, functionally, Chinese calligraphy does not represent a particular culture or religion (Tionghoa, 2016). In this case, calligraphy has the same function as other types of art: to express things felt by the artist that can come from the artist's imagination.

The position of calligraphy in Chinese culture is considered as high art, its position is higher than painting. Suryajaya (2016, p.254) explains this with the reason that in Chinese culture, aesthetics are the inner expressions of artists, not representations of external reality. Chinese painting is representational, meaning that painting depicts 
things that are seen and exist in reality, therefore are not valued as high art. New painting is valued as a high work of art when the artists apply the calligraphic brush strokes in their works. The brush stroke on Chinese calligraphy and painting is appreciated as an artist's personal expression, the most important aesthetic element in a work of art. Chandler (2017, p.126) explains that scholars since the Song dynasty (960-1279) has been assuming that the expression of brush stroke in artworks can express the subtlest emotions and cosmic patterns as in Taoist teachings.

The brush stroke which is the most important aesthetic element in calligraphy is inseparable from the material used, known as the "four treasures" (wenfang sibao). The four treasures refer to the four main items of calligraphy art supplies: brush (mao bi), solid ink (mo), ink bowl (yantai) and paper (xian zhi). The use of calligraphy art equipment sets is one of the benchmarks to identify whether a work can be assessed as calligraphy or not. An example for this is the classification of Chinese calligraphy avant-garde which has the characteristics of using material that is not included in the four materials in the "four treasures", such as: performance, dance, multimedia art and graffiti (Lezzi, 2015, p.214).

Chinese traditional art has experienced significant changes in the past century. Marked by the cultural revolution initiated by Mao Zedong to the avant-garde art aggression that succeeded in dominating the global market, the question of the future of traditional Chinese art became a matter of debate, especially in terms of cultural values between Guohua (traditional Chinese painting) and Xihua (painting/West). Debate in the aesthetic sphere also occurs especially regarding the possibility of the emergence of the assumption that the calligraphy brushstroke is no longer important, even disappearing, or fused with Western aesthetic principles (Chandler, 2017, p.148).

Interactions that occur between Chinese art, especially calligraphy art with Western art on a global scale produce a phenomenal discourse: Chinese modern calligraphy art. The emergence of Chinese modern calligraphy is an inevitable consequence of various forms of interaction such as art experiments conducted by calligraphy artists. As a result, the development of calligraphy has increasingly moved away from strict traditional standards and rules, even further away from the kanji characters commonly used in Chinese calligraphy (Lezzi, 2015, p.206).

\subsection{The uniqueness of Foo Yong Kong's paintings}

Foo Yong Kong (b.1948) is a Malaysian artist who has educational background both in Chinese calligraphy and modern painting. Foo took a formal arts education at the Malaysia Institute of Art (MIA) (1969-1971). Previously he studied fine arts in Classical Oriental Art. At MIA, Foo studied with a famous Malaysian artist: Chun Chen Sun, Chun taught him Chinese painting and calligraphy. In addition to exploring painting and calligraphy, at MIA Foo also explores Western painting using oil paints and other mediums. Since the 70s, Foo has been obsessed with efforts to integrate the practice of Chinese calligraphy and Western painting. The works resulting from Foo's efforts were first exhibited at his solo exhibition at Samad Art Gallery, Malaysia. The works in this exhibition show the harmonization between the expressively strong and loose calligraphy brush stroke with geometric shapes inspired by Western formalism painting (figure 1)

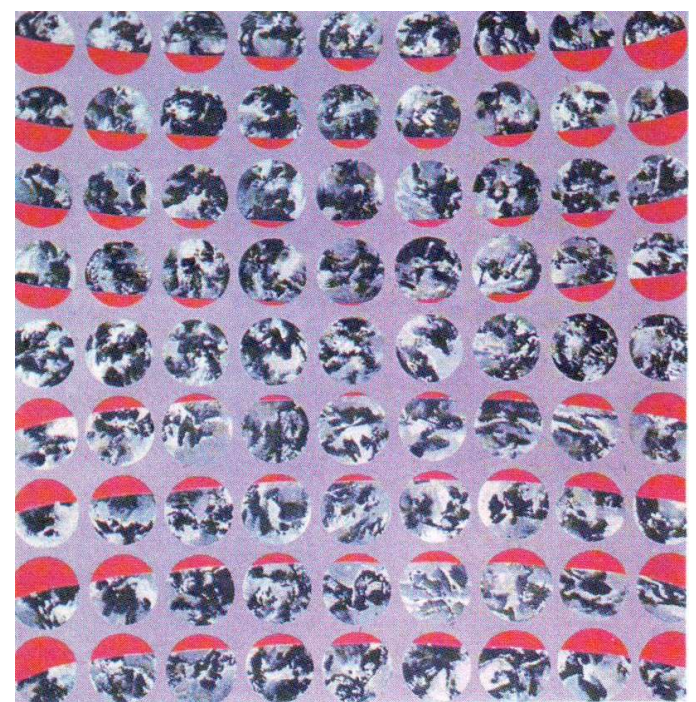

Figure 1. one of Foo's painting in Samad Gallery

The creation process of Foo's artwork in the following decades cannot be separated from the concept of fusion 
between aesthetic elements of Chinese calligraphy and Western painting. Foo called this painting concept "a new type of painting". This study aims to analyse the aesthetic tendencies of Foo Yong Kong's paintings in the perspective of Chinese modern calligraphy.

\section{Method}

The method used in this research is a qualitative method which consists of a literature study on the biography of Foo Yong Kong and his works, the aesthetic value of Chinese calligraphy and Chinese modern calligraphy. Literature studies are also carried out regarding eclecticism as one of the aesthetic characteristic of contemporary art. Direct observations and interviews were carried out with a visit to the Foo Yong Kong studio in Malaysia. The method of analysis of works is done by using the structure of critical art writing: the critical performance (Feldman, 1992, p.487) consisting of description, formal analysis, interpretation and evaluation. The object of analysis is one of the works exhibited at the solo exhibition Foo Yong Kong entitled "East / West Fusion" (1999), Rusli Hashim Fine Art, Malaysia. The reason for choosing the object is because the works at the exhibition specifically exhibit Foo's works that combine aesthetic elements of Chinese calligraphy and Western painting. The discourse explicitly becomes the title of the exhibition.

\section{Analysis}

\subsection{Chinese modern calligraphy as discourse}

The definition of Chinese modern calligraphy began to be used when the practice of traditional Chinese art politically interacted with modern art (Chandler, 2017, p.148). Lezzi (2015, p.207) formulated the definition of Chinese calligraphy by defining each of the meanings of calligraphy (shu fa), Chinese (Zhung guo), modern (Xian dai) separately. This formulation is not without problems because of the fact that the debate about modern Chinese calligraphy is still exclusive. The Lezzi formula $(2015$, p.211) summarizes some of the dialectical debates and hypotheses of Chinese art critics who are mostly published in Chinese language by Chinese art experts who are also Chinese. Within 24 people who put forward hypotheses regarding modern Chinese calligraphy, only 3 people are Western critics. The Chinese art critics are art academics from government university sponsored by the Chinese government, this causes the discourse of modern Chinese calligraphic art to be exclusive and difficult to be appreciated globally (Lezzi, 2015, p.213).

The term calligraphy ( $s h u f a$ ) was formulated by Lezzi $(2015$, p.208) as art which is divided into two parts: verbal art and abstract art. Verbal art is the art of writing Chinese characters, abstract art is intended by Lezzi as the art of painting lines. In this case, Lezzi sees calligraphy in two aspects: textual and visual aspects. The term China (Zhong guo) is defined referring to the aesthetic characteristics of Chinese calligraphy: Zhong Guo Xing (Chinese/Chineseness), this character is a very important and fundamental aspect in Chinese calligraphy that distinguishes it from calligraphy from other countries, like Japan for example. The term modern (Xian dai) is defined temporally and culturally. Temporally means according to periodization, referring to the modern age in China, which it's exact time is still debated by art critics. Whereas culturally, modern is interpreted as something that is contrary to the value of tradition in the art of calligraphy.

The conclusion of Lezzi's formulation $(2015$, p.214) in classifying Chinese modern calligraphy is accumulated into two classifications: The modernist and avant-garde. The modernist classification focuses on exploration of style in calligraphy, which is characterized by three different tendencies: (1) pictorial-pictographic tendencies; (2) towards new spatial abstractions and compositions; and (3) calligraphy collages. Avant-garde classification is a trend that aims to radically change calligraphy. Conceptual current carries the "calligraphy deconstruction", its where the Chinese characters can no longer be recognized and read, or because the focus of the work lies in the beauty of abstract calligraphic lines. Calligraphy deconstruction also includes the tendency to use mediums other than the ink, brushes, ink stone and paper such as performance art, dance, multimedia art and graffiti.

\subsection{Eclecticism as a characteristic of post-modern aesthetic}

Contrary to avant-garde which has the concept of being ahead of time, postmodernism has the opposite spirit, it appreciates existing ones, then mixed, combined to produce eclectic characteristics (Yustiono, 1994, p.118). Piliang $(2003$, p.15, 253) defines eclecticism as a tendency in literature, art, design and architecture, in the form of combining a style or code with another style and visual codes that are completely different in character or has multiple codes. Eclecticism is against the spirit of originality, individual genius or grandeur which is the principles 
of modern art concepts (Sugiharto, 2015, p.36).

\subsection{Foo Yong Kong painting: Eclecticism in modern Chinese calligraphy}

The work entitled A Moment with Nature II features a composition consisting of black brushstrokes and a series of transparent colours of blue, yellow and brown overlapping one and another. Black brushstrokes are done using calligraphy brushes and Chinese ink. The series of contrasting colours as background is done using acrylic paint with transparent techniques, so that an opaque black brushstroke in the centre of the image area becomes the focus as well as the foreground.

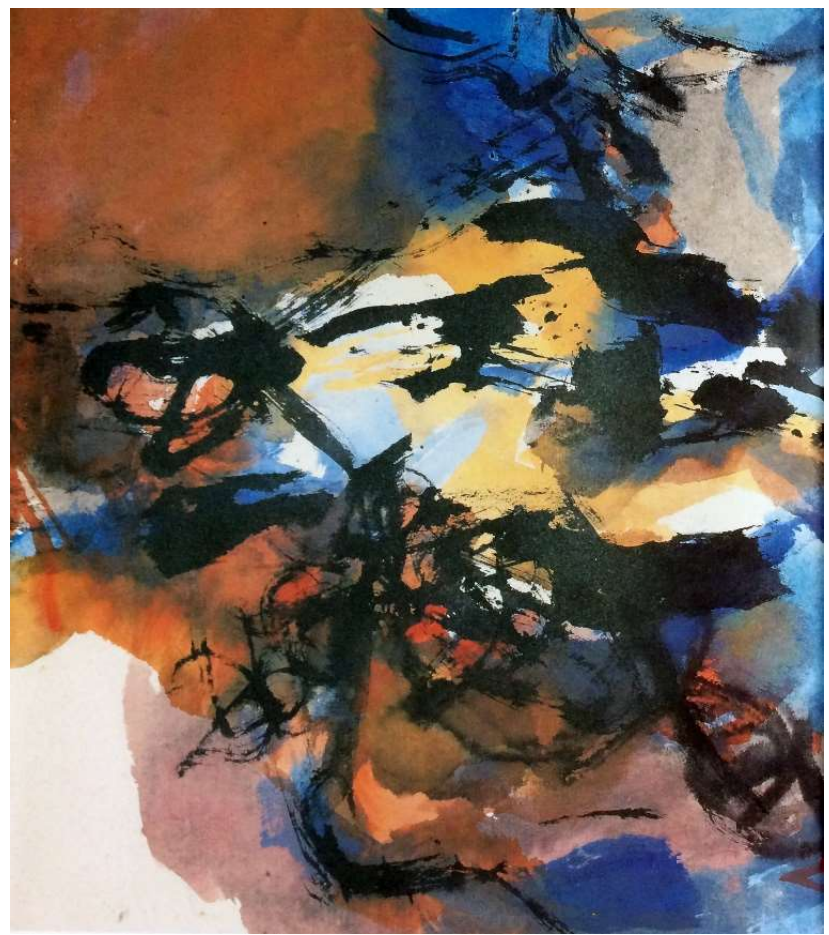

Figure 2. A Moment with Nature II. Ink, acrylic on paper, 56 x 45 cm. 1999

Black brushstrokes have characteristics similar to Chinese calligraphy: Solid, spontaneous strokes that form a composition of broken lines, expressive and firm, some form curves, others form broken straight lines. Strong and spontaneous visual effects are the result of energy impulses generated from the hands of the artist, directly on paper, the characteristic of calligraphy art. This characteristic is the most important visual element of Foo. Foo called this calligraphic brush stroke as the "backbone" of each of his works.

The composition of colours that has function as background is made with transparent techniques, using acrylic paint. These colours are mostly primary colours such as yellow, blue and red and overlapping with other colour layers to form new colours, its similar to the wet technique in painting watercolours, where the image area is processed in a wet state, and the transparent colours are produced, absorbed, forming harmonious patterns. Foo called this technique the "drip effect", referring to an effect similar to the colour pigments dripped on wet paper or cloth that cause colours to fade and form beautiful transparent patterns. Foo deliberately chose special paper that is commonly used for calligraphy, the rice paper, because it is easy to absorb water and produce visual effects as mentioned above. Foo fully understands the artistic potential of each material he uses, this is due to the exploration of material he has worked on for decades. In the action painting discourse, this tendency to process materials as artistic elements in the work is called mattiere (Diyanto in Sugiharto, 2015, p.69)

\section{Conclusion}

Foo's work is in accordance with one of Lezzi's Chinese modern calligraphy tendencies: The avant-garde Chinese modern calligraphy. The hallmark of this tendency lies in the focus of the abstract aspects of calligraphic lines. The principle of deconstruction of calligraphy also occurs in Foo's work, because Chinese characters or letters of 
the alphabet are no longer visible. However, what's interesting is that the deconstruction of calligraphy in Foo's works is not completely independent of traditional aspects, because Foo still uses materials such as Chinese ink, brushes calligraphy and paper. Foo even managed to make a harmonious blend between the special use of calligraphy and the acrylic paint technique he used, the effect resulting from the technique he called "drip effect".

The strongest tendency of Foo's work lies precisely in the harmonious blend of Chinese calligraphy and abstract expressionism which actually contradicts one another. This tendency is identical with one of the characteristics of post-modern art: eclecticism.

\section{Reference}

Chandler, M. (2017). Expressing the heart's intent: Explorations in Chinese aesthetic. New York: SUNY press

Chiang, Y. (2009). Chinese calligraphy. Available at : https://www.britannica.com/art/Chinese-calligraphy (accessed: 14 August 2016)

Chinese calligraphy (2016) Available at: https://en.wikipedia.org/wiki/Chinese calligraphy (accessed: 14 August 2016)

Diyanto. (2017). Seni lukis dan obsesi abadinya. In B. Sugiharto (ed.), Untuk apa Seni? (3 ${ }^{\text {rd }}$ ed., pp. 47-110). Bandung: Pustaka Matahari

Feldman, E. B. (1992). Varieties of Visual Experience. Englewood Cliffs, NJ: Prentice-Hall

Lezzi, A. (2015). What is Chinese modern calligraphy?: An exploration of the critical debate on modern calligraphy in contemporary china. Journal of Literature and Art Studies, 5(3), 206-216

Piliang, Y. (2003). Hipersemiotika: Tafsir cultural studies atas matinya makna. Yogyakarta: Jalasutra

Shufa (书法) : Asal Usul Seni Kaligrafi Tiongkok (Chinese Calligraphy) (2015). Available at:

https://www.tionghoa.info/asal-usul-seni-kaligrafi-tiongkok/ (accessed: 14 August 2016)

Sugiharto, B. (ed.). (2015). Untuk apa Seni? (3 ${ }^{\text {rd }}$ ed.). Bandung: Pustaka Matahari

Suryajaya, M. (2016). Sejarah estetika: Era klasik sampai kontemporer. Jakarta: Gang Kabel dan Indie Book Corner

Moore, W. (1999). In Rejection of the Classical-Creating an East/West Fusion (Catalogue). Rusli Hashim Fine Art-Malaysia

Yustiono. (1994). Setelah “pemberontakan” seni rupa. Jurnal Kalam, 3, 118 